Munro Kerr: Relative Sizes of Maternal Pelvis, \&e. 227

\title{
Note on a New Method of Estimating the Relative Sizes of the Maternal Pelvis and Fœtal Head.
}

\author{
By J. M. Munro Kerr, \\ Obstetric Physician, Glasgow Maternity Hospital.
}

IN the April number of the Journar of last year I described a method for estimating the relative sizes of foetal head and maternal pelvis, and pointed out the importance of making that the basis of treatment in moderate degrees of pelvic deformity. Unfortunately the illustrations which should have appeared were not reproduced.

The method described was in many respects a combination of those recommended by Müller and Pinard. In referring to Müller's method I made certain mistakes in my description of it, and was very glad indeed to be corrected, and in so kindly a manner, by Dr. Koenig, whose note on the subject appeared in the September number of the Jodrnal. Since then I have had some correspondence with Dr. Koenig. I learned from him that although in many respects Müller's and my method resembled each other, in two very important points indeed they differed. The two points which I refer to are the grasping with the left hand the foetal head by a Pawlic grip by which one pushes the head into the pelvis, and the feeling with the thumb of the hand that is examining vaginally the amount of overlapping of the head at the brim. The illustration explains this.

I have no wish to magnify the importance of the modification described; I do, however, think it is a distinct improvement upon Müller's method. 